\title{
Abortion and contraception practices in COVID-19 era
}

\author{
Bharti Maheshwari, G. S. Manchanda, Preeti Sharma*, Taniya Setiya
}

Department of Obstetrics and Gynecology, Muzaffarnagar Medical College, Muzaffarnafar, Uttar Pradesh, India

Received: 09 February 2021

Revised: 01 April 2021

Accepted: 03 April 2021

\author{
*Correspondence: \\ Dr. Preeti Sharma, \\ E-mail: drpreetisharma.sharma@gmail.com
}

Copyright: $@$ the author(s), publisher and licensee Medip Academy. This is an open-access article distributed under the terms of the Creative Commons Attribution Non-Commercial License, which permits unrestricted non-commercial use, distribution, and reproduction in any medium, provided the original work is properly cited.

\begin{abstract}
Background: To protect the gains made in sexual and reproductive health in over the past several decades, care for childbearing women and newborn infant's needs to continue during the pandemic. The provision of safe abortion and contraceptive services remains critical. When staff and services are under extreme stress there is a real risk of increasing avoidable harm. Aim and objectives were to determine the effect of COVID-19 on accessibility and acceptance of contraception and safe abortion care services.

Methods: Questionnaire survey was Done among 500 women in 6 months from April to September 2020, on availability and utilization of safe abortion and contraception services during lock down in covid time from patients getting treatment by Department of Obstetrics and Gynecology, Muzaffarnagar Medical College and health care workers (paramedics and others staff) of reproductive age group working in the institute.

Results: Majority (56\%) of women were in the age group of 20-30 years. $70 \%$ of women have access to contraception at present while it was reduced to $60 \%$ during lockdown. Most commonly used method was barrier method (70\%) followed by OCP's which they could avail maximum from pharmacy (40\%). 65\% of women had access to post delivery and post abortion contraception with most common method adopted being injectables, in $3 \%$ cases IUCD was inserted, 1\% ligation with LSCS. Among them 42 cases were covid positive who underwent caesarean section and adopted contraception thereafter with tubal ligation in 2 cases. In this study $32 \%$ of women had unwanted pregnancy, among them 35\% underwent surgical abortion $61 \%$ medical abortion and $4 \%$ continued pregnancy.

Conclusions: The COVID-19 pandemic has impacted safe abortion and contraception services. Unwanted pregnancy increased to $32 \% .62 \%$ subjects claimed for accessibility at government centre and door to door by health worker.
\end{abstract}

Keywords: Abortion, Contraception, COVID-19 pandemic, Sexual and reproductive health, Unwanted pregnancy

\section{INTRODUCTION}

In Wuhan China, the first COVID-19 patient was reported in the end of the December 2019 and then spread rapidly all over the world. ${ }^{1}$ COVID-19 is considered as a third kind of corona virus causing severe pneumonia, the first two virus which causes severe pneumonia are severe acute respiratory syndrome coronavirus (SARS-CoV) and Middle East respiratory syndrome coronavirus (MERS$\mathrm{CoV})$. No area of healthcare and other is immune to the impact of COVID-19. ${ }^{2-4}$
The sexual and reproductive health (SRH) has affected by Covid-19 pandemic worldwide in positive and negative ways. Home isolation led to decreased SRH services due to fears of contracting the virus, partner violence report increased, and there is reduced contraception and safe abortion in some health care settings. ${ }^{5}$

Reproductive health services like abortion and contraception have reduced globally. In 114 low and middle income countries including India 47 million women will not be able to use contraception and this 
would result in 7 million unintended pregnancies as per technical note of UNFPA. ${ }^{6}$

According to a study, In India, approximately 15.6 million abortions happen annually, out of which $73 \%$ are through drugs accessed outside facilities, $16 \%$ in private health services, $6 \%$ in public health facilities and $5 \%$ through traditional unsafe methods. ${ }^{7}$

As we all know unsafe abortion is the leading cause of maternal mortality. World Health Organization has classified abortions safe and unsafe as: Abortion is safe when the abortions are done by the trained person with a proper method recommended by WHO. In these, subjects use tablets (medical abortion) or a simple outpatient procedure at a facility with required infrastructure. Abortion is unsafe, when the procedure is done either by untrained or unskilled persons, less safe when the abortion done by drugs outside a health facility after buying with a chemist. In India, it is estimated that about $73 \%$ of abortion are less safe.

Family planning programmes impact women's health by providing universal access to sexual and reproductive healthcare services and counselling information. FP also has far-reaching benefits which transcend health, impacting all 17 sustainable development goals (SDGs). A women's access to her chosen planning method strongly aligns with gender equality. Birth spacing can have great implications on health, as an example, reduction in malnutrition (goal 2) and long-term physiological condition (goal 3) for the mother and also the child. ${ }^{8}$

It has become a challenge to ensure continuity of reproductive health care to women and girls in this era of pandemic. Hence the aim of this study was to determine the effect of COVID-19 on contraception and safe abortion care services at Muzaffarnagar Medical College and Associated Hospital.

\section{METHODS}

The present study was carried out in the Department of Obstetrics and Gynecology, Muzaffarnagar Medical College and Associated Hospital Muzaffarnagar from April 2020 to September 2020. Total 500 women of reproductive age group were selected for this study. Questionnaire survey was done to know about status of accessibility and acceptance of safe abortion and contraceptive services during lock down from patients getting treatment by department of Obstetrics and Gynecology Muzaffarnagar Medical College and health care workers (paramedics and others staff) of reproductive age group working in the institute.

\section{Source of data}

Tele OPD patients, covid positive patients of (Obstetrics and Gynecology Department), healthcare workers (paramedics and others) working in the institute at Muzaffarnagar Medical College and Hospital, Muzaffarnagar.

\section{Statistical analysis}

The data was entered into the Microsoft excel and the statistical analysis was performed by statistical software SPSS version 21.0. The quantitative (numerical variables) were present in the form of mean and SD and the qualitative (categorical variables) were present in the form of frequency and percentage. The student $t$ test was used for comparing the mean values between the 2 groups whereas chi-square test was applied for comparing the frequency. The $\mathrm{p}$ value was considered to be significant when less than 0.05 .

\section{RESULTS}

Six months data (April-September) 2020 were collected for this study. Safe abortion and contraception services during six months of the pandemic were assessed. Majority of women were in the age group of 20-30 years $(56 \%), 24 \%$ women in the age group of $31-35$ years and $20 \%$ in the age group of 36-40 years. Out of 500 studied participants, 250 were below 08th standard, 125 were educated till 12th and 125 were graduate and above. 300 women were house wife, 125 were health workers and 75 are other field workers (Table 1).

Table 1: Demographics study of all the participants.

\begin{tabular}{|c|c|c|c|}
\hline Variables & & $\begin{array}{l}\text { No. of the } \\
\text { subjects }\end{array}$ & Percentage \\
\hline \multirow{3}{*}{ Age (years) } & $20-30$ & 280 & 56 \\
\hline & $31-35$ & 120 & 24 \\
\hline & $36-40$ & 100 & 20 \\
\hline \multirow{3}{*}{$\begin{array}{l}\text { Education } \\
\text { status }\end{array}$} & $<8^{\text {th }}$ & 250 & 50 \\
\hline & Till $12^{\text {th }}$ & 125 & 25 \\
\hline & $\begin{array}{l}\text { Graduate and } \\
\text { above }\end{array}$ & 125 & 25 \\
\hline \multirow{3}{*}{ Occupation } & Housewife & 300 & 60 \\
\hline & Health worker & 125 & 25 \\
\hline & $\begin{array}{l}\text { Other field } \\
\text { worker }\end{array}$ & 75 & 15 \\
\hline
\end{tabular}

Table 2: Showing the number of contraception users.

\begin{tabular}{|lll|}
\hline At present & 350 & $\mathbf{7 0 \%}$ \\
\hline Before march & 330 & $73 \%$ \\
\hline During lockdown & 310 & $62 \%$ \\
\hline
\end{tabular}

$62 \%$ of the total participants had accessibility to contraception during lockdown (Table 2). Majority of women availed from government hospital (36\%), 32\% were from pharmacy, 26\% from Asha and ANM and 8\% from private hospital (Table 3). $70 \%$ women were adopted barrier contraception method, $14 \%$ injectables, 
$12 \%$ OCPs, $3 \%$ IUCD and $1 \%$ adopted sterilization (Table 4).

Table 3: Showing the site of accessibility of contraception during lockdown.

\begin{tabular}{|lll|}
\hline Site & Number & Percentage \\
\hline ASHA, ANM & 81 & 26 \\
\hline Pharmacy & 93 & 32 \\
\hline Government hospital & 111 & 36 \\
\hline Private hospital & 25 & 8 \\
\hline
\end{tabular}

Table 4: Represent adopted method of contraception among participants.

\begin{tabular}{|lll|}
\hline Methods & Number & Percentage \\
\hline Barrier method & 217 & 70 \\
\hline OCP'S & 37 & 12 \\
\hline Injectables & 43 & 14 \\
\hline IUCD & 10 & 3 \\
\hline Sterilization & 3 & 1 \\
\hline
\end{tabular}

Table 5: Showing use of contraception adoption postdelivery and abortion.

\begin{tabular}{|lll|}
\hline Contraception used & Number & Percentage \\
\hline Yes & 325 & 65 \\
\hline No & 175 & 35 \\
\hline
\end{tabular}

Table 6: Post-delivery and abortion method of contraception.

\begin{tabular}{|lll|}
\hline Methods & Number & Percentage \\
\hline PPIUCD & 32 & 10 \\
\hline Injectables & 130 & 40 \\
\hline POP'S & 32 & 10 \\
\hline LAM & 113 & 35 \\
\hline Sterilization & 13 & 4 \\
\hline
\end{tabular}

$65 \%$ of women had access to post delivery and post abortion contraception with most common method adopted being injectables (40\%), in 3\% cases IUCD was inserted, $1 \%$ ligation with LSCS (Tables 5 and 6). There were $32 \%$ women having unwanted pregnancies (Table 7). Among all the studied women, $61 \%$ underwent medical abortion, 35\% ended up with surgical abortion and $4 \%$ continued their pregnancy (Table 8). Among all the 500 women, 42 cases were COVID positive who underwent caesarean section and adopted contraception thereafter with tubal ligation in 2 cases.

Table 7: Showing the unwanted pregnancy among studied subjects.

\begin{tabular}{|lll|}
\hline Unwanted pregnancy & Number & Percentage \\
\hline Yes & 160 & 32 \\
\hline No & 340 & 68 \\
\hline
\end{tabular}

Table 8: Showing the outcome of unwanted pregnancy.

\begin{tabular}{|lll|}
\hline Outcome & Number & Percentage \\
\hline Medical abortion & 98 & 61 \\
\hline Surgical abortion & 56 & 35 \\
\hline Continued pregnancy & 6 & 4 \\
\hline
\end{tabular}

\section{DISCUSSION}

In the present study, the majority $(56 \%)$ of women were in the age group of 20-30 years. $70 \%$ of women have access to contraception at present while it was reduced to $60 \%$ during lockdown. Most commonly used method was barrier method $(70 \%)$ followed by OCP's which they could avail maximum from pharmacy (40\%). $65 \%$ of women had access to post delivery and post abortion contraception with most common method adopted being injectables, in 3\% cases IUCD was inserted, $1 \%$ ligation with LSCS. Among them 42 cases were covid positive who underwent caesarean section and adopted contraception thereafter with tubal ligation in 2 cases.

In the present study, 32\% of women had unwanted pregnancy, among them $35 \%$ underwent surgical abortion $61 \%$ medical abortion and $4 \%$ continued pregnancy. $62 \%$ subjects claimed for accessibility at government centre and door to door by health worker.

During pandemic, contraception and abortion services were available but there was difficulty in accessibility due to lockdown. In our study, there were decrease in the use of contraception up to $60 \%$ during six months and also there is reduction in the safe abortion care during that period. Adoption of contraception post-delivery and abortion accounted for $65 \%$ and $32 \%$ had unwanted pregnancy. Postpartum and post-abortion family planning are strongly considered essential during the pandemic, especially as one can use the opportunity to provide care while the patient is already in a health facility.

A similar study was conducted by Bateson et al in the United States (US), Canada, UK, France, Australia, Scandinavia, China, South Africa and Nepal and predictions were made about higher rates of unintended pregnancy, unsafe abortion. Some countries have been able to maintain LARC access through brief procedural visits with appropriate personal protective equipment (PPE) following a virtual consultation. ${ }^{9}$

Abortion regulations in England, Scotland and Wales now allow home administration of both mifepristone and misoprostol supported by telemedicine, while regulatory changes have extended the upper gestational limit from 9 to 10 weeks in Finland, to 12 weeks in Scotland and from 7 to 9 weeks in France. ${ }^{10}$

A study performed by Belay et al, in Ethiopia from March to May 2020 concluded that the number of deliveries, safe abortion, post abortion family planning 
and postpartum family planning reduced by $27.6 \%$, $16.4 \%, 40.5 \%$ and $66.7 \%$ respectively. ${ }^{11}$

Number of public sector facilities for routine health management information system (HIMS) decreased all over India from December 2019 to March 2020. The secondary health care facilities provided by district hospital reduced by $32 \%$ and primary health facility near the community reduced by $14 \% .^{12}$

As per the government of India, the injectable contraception dose decreased by $36 \%$, intrauterine device (IUD) by $21 \%$ in the same duration. The decrease in the safe abortion was reduced to $28 \%$. Distribution of combined oral pill cycles and condom pieces were similarly reduced by $15 \%$ and $23 \%$, respectively. ${ }^{13}$

The usefulness of the study may be limited because the area of collection of the data is narrow. Also collecting data from the patient during tele OPD may be limited.

\section{CONCLUSION}

The COVID-19 pandemic has impacted safe abortion and contraception services. Though both contraception and abortion services were available but there was extreme difficulty in accessibility due to restrictions of lockdown. Though abortion care and contraceptive services during the pandemic was prioritized by government from very beginning, but unwanted pregnancy increased. Additionally, health care providers should be reoriented; resources and staff must be maintained to ensure continuation of the service amid COVID-19 pandemic.

Funding: No funding sources

Conflict of interest: None declared

Ethical approval: The study was approved by the Institutional Ethics Committee

\section{REFERENCES}

1. Huang C, Wang Y, Li X, Ren L, Zhao J, Hu Y, et al. Clinical features of patients infected with 2019 novel coronavirus in Wuhan, China. Lancet. 2020;395(10223):497-506.

2. Chen N, Zhou M, Dong X, Qu J, Gong F, Han Y, et al. Epidemiological and clinical characteristics of 99 cases of 2019 novel coronavirus pneumonia in Wuhan, China: a descriptive study. Lancet. 2020;395:507-13.

3. Wang D, Hu B, Hu C, Zhu F, Liu X, Zhang J, et al. Clinical characteristics of 138 hospitalized patients with 2019 novel coronavirus-infected pneumonia in Wuhan, China. JAMA. 2020;323:1061-9.
4. Liu K, Fang YY, Deng Y, Liu W, Wang MF, Ma JP, et al. Clinical characteristics of novel coronavirus cases in tertiary hospitals in Hubei Province. Chin Med J. 2020.

5. Contraception and COVID-19. Disrupted supply and access. Available from: https://www.ippf.org/blogs/contraception-and-covid19-disrupted-supply-and-access. Accessed on 15 April 2020.

6. UNFPA, with contributions from Avenir Health, Johns Hopkins University (USA) and Victoria University (Australia). Interim Technical Note. Impact of the COVID-19 pandemic on family planning and ending gender-based violence, female genital mutilation and child marriage. Pandemic threatens achievement of the Transformative Results committed to by UNFPA. Available from: https://www.unfpa.org/resources/impact-covid-19pandemic-family-planning-and-ending-genderbased-violence-female-genital. Accessed on 27 April 2020.

7. Singh S, Shekhar C, Acharya R, Moore AM, Stillman M, Pradhan MR, et al. The incidence of abortion and unintended pregnancy in India, 2015. Lancet Glob Health. 2018;6:e111-20.

8. Starbird E, Norton M, Marcus R. Investing in family planning: Key to achieving the sustainable development goals. Glob Health Sci Pract. 2016;4:191-210.

9. Bateson DJ, Lohr PA, Norman WV, Moreau C, Danielsson KG, Paul D, et al. The impact of COVID19 on contraception and abortion care policy and practice: experiences from selected countries. BMJ Sex Reprod Health. 2020;46:241-3.

10. Royal College of Obstetricians and Gynaecologists. Coronavirus (COVID-19) infection and abortion care. London: Royal College of Obstetricians and Gynaecologists; 2020.

11. Belay L, Hurisa T, Abbas F, Daba M, Abebe B, Nigatu B, et al. Effect of covid-19 pandemic on safe abortion and Contraceptive services and mitigation measures: a case Study from a tertiary facility in ethiopia. Ethiopian J Reprod Health. 2020;12(3):517.

12. Vora KS, Saiyed S, Natesan SK. Impact of COVID19 on family planning services in India. Sex Reprod Health Matters. 2020;28(1): 1785378.

13. Data Reporting Status All India level data, 20192020 Standard reports. Health Management Information System (HMIS). Ministry of Health and Family Welfare, Government of India. Available from https://nrhmmis.nic.in/hmisreports/frmstandard_reports.aspx. Accessed on 29 April 2020.

Cite this article as: Maheshwari B, Manchanda GS, Sharma P, Setiya T. Abortion and contraception practices in COVID-19 era. Int J Reprod Contracept Obstet Gynecol 2021;10:1874-7. 